\title{
Collagenous gastritis: Gastroesophageal reflux disease in an adult patient without collagenous colitis
}

\author{
Yousef Usta, Denise Millstine, Fredrick Kenny
}

\begin{abstract}
Introduction: Collagenous gastritis, first described in 1989, is a very rare disease with only about 50 cases ever reported to date. This is a histologic diagnosis characterized by a thickened subepithelial collagen bands in the gastric mucosa. It is associated with an inflammatory infiltrate with mixed chronic inflammatory infiltrate of the lamina propria and surface epithelial damage. We present an adult case with symptoms of reflux that does not fit the recent literature that has combined all adult collagenous gastritis cases with collagenous colitis and chronic watery diarrhea. Case Report: A 55-year-old female presented to us with chronic heart burn. She was clinically diagnosed with gastroesophageal reflux disease. Upper endoscopy was done and she was found to have gastric and gastroesophageal junction collagen deposits on biopsy. She did not have collagenous colitis on colonoscopy biopsies or any other systemic disease and she denied any lower gastrointestinal symptoms including diarrhea. All the blood tests performed were normal. Conclusion: To the best of our knowledge, this is the first case of collagenous involvement of the esophageal gastric junction in addition to
\end{abstract}

Yousef Usta', Denise Millstine ${ }^{2}$, Fredrick Kenny ${ }^{3}$

Affiliations: ${ }^{1} \mathrm{MD}$, Internal Medicine, Mayo Clinic Scottsdale, 13400 E. Shea Blvd. Scottsdale, AZ 85259; '2DO, Internal

Medicine, St Joseph Hospital and Medical Center, 350 West Thomas Rd Phoenix, Arizona, 85013; ' MD, Gastroenterology, St Joseph Hospital and Medical Center, 350 West Thomas Rd Phoenix, Arizona, 85013.

Corresponding Author: Yousef Usta, 3302 N 7th St Apt 248. Phoenix Arizona, 85014 USA; Ph: 6023089575; Email: yosusta@hotmail.com

Received: 21 March 2013

Accepted: 05 August 2013

Published: 01 December 2013 the stomach. It is the first case of collagenous gastritis in an adult patient presenting with upper gastrointestinal symptoms without collagenous colitis, which is usually only seen in pediatric type disease. Considering the rarity of the disease, we feel that is still too premature to categorize collagenous gastritis into two distinct adult type and pediatric type disease.

Keywords: Collagenous gastritis, Collagenous colitis, Gastroesophageal reflux disease, Malabsorption, Diarrhea

$* * * * * * * * *$

Usta Y, Millstine D, Kenny F. Collagenous gastritis: Gastroesophageal reflux disease in an adult patient without collagenous colitis. International Journal of Case Reports and Images 2013;4(12):678-681.

$* * * * * * * * *$

doi:10.5348/ijcri-2013-12-409-CR-3

\section{INTRODUCTION}

Collagenous gastritis, first described in 1989 [1], is a very rare disease with only about 50 cases reported to date [2]. This is a histologic diagnosis characterized by thickened subepithelial collagen bands in the gastric mucosa associated with an inflammatory infiltrates [3]. Recent case reports have started grouping cases into two major groups with distinct clinical presentations seen in children and adults, and adult type disease [2, 4-6]. The two groups are described as children or young adults presenting with isolated collagenous gastric disease with anemia and gastric nodularity on endoscopy and the other distinct group includes older adults with both collagenous gastritis (CG) and collagenous colitis (CC) associated with chronic diarrhea and erythema on colonoscopy [6]. The incidence of $\mathrm{CC}$ has increased significantly over time 
and is much more commonly seen than CG. Patients with $\mathrm{CC}$ tend to present with lower gastrointestinal symptoms including pain, bloating, diarrhea, and malabsorptive symptoms [7]. Since most adults present with both CC and CG, there is likely a common factor that causes both disease processes. We present an adult case that does not meet the adult type categorization of CG. Our case is a 55-year-old female who presented with symptoms of gastroesophageal reflux disease (GERD) and no lower gastrointestinal symptoms. Our case did not fit the recent literature that has categorized all adult CG cases with CC, chronic watery diarrhea, and other systemic diseases. Considering the rarity of the disease, we feel that it is still too premature to categorize the patients into these two distinct groups based on age or upper and lower gastrointestinal symptoms.

\section{CASE REPORT}

Herein, we present a 55-year-old female with a 10year history of reflux and heartburn. Her past medical history includes iron deficiency anemia that responded to iron supplements, osteoporosis, and a resected acoustic neuroma 20 years before. Family history was negative for gastrointestinal diseases. She denied odynophagia, nausea, vomiting, or anorexia. She denied fever, chills, diarrhea, weight loss, hematochezia, or melena. She denied aspirin, nonsteroidal antiinflammatory medications, alcohol abuse, or any toxic chemical ingestion. All laboratory examinations were normal including antithyroid antibody, antiparietal cell antibodies, anti tissue transglutaminase, thyroid stimulating hormone, erythrocyte sedimentation rate, complete metabolic panel, and complete blood count.

An esophagoduodenoscopy (EGD) was performed which showed a grossly normal esophagus and duodenum. Grossly, the stomach had abnormal vascularity and atrophy of the mucosa with no bleeding. Biopsies performed on the duodenum showed no evidence of celiac disease. Histology of the antrum of the stomach showed evidence of chemical gastropathy. There was villiform transformation and muscular stranding along mucosal congestion with no acute or chronic inflammation. Biopsy results were negative for Helicobacter Pylori, and there was no evidence of intestinal metaplasia, abnormal infiltrate, or neoplasia. Biopsies of the body and fundus of the stomach showed evidence of chronic atrophic gastritis, patchy collagenous deposits, focal lymphocytic gastritis, severe mucosal atrophy and fibrosis, and focal intestinal metaplasia. Some of the tissue showed an intense lymphoplasmacytic infiltrate in the lamina propria which in some places completely replaces the glandular mucosa. There were a very large number of plasma cells and beta cells seen but the majority of the cells were $\mathrm{T}$ cells. There was marked deposition of collagen beneath the surface in many of the areas particularly where there was significant epithelial destruction seen with trichrome staining. There was fibrosis in the muscularis mucosa underlying the area of amplified mucosa, and there was no sign of autoimmune gastritis secondary to the presence of intact portions of oxyntic mucosa. A section of the gastroesophageal junction showed similar changes seen in the stomach. There was an area of fibrosis under the luminal surface consistent with collagen deposits, which may be consistent with collagenous esophagitis CE (Figure 1). She had two colonoscopies performed with random biopsies to rule out accompanying collagenous colitis, and all the biopsies showed normal mucosa. There was no evidence of $\mathrm{CC}$ and the colon appeared grossly normal.

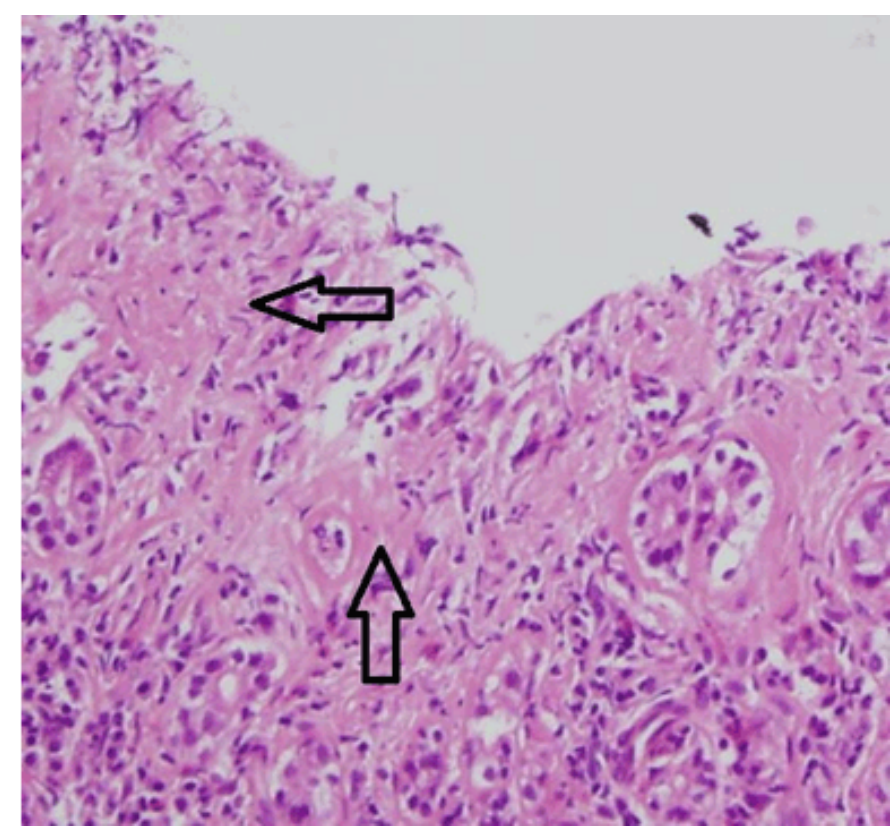

Figure 1: A photomicrograph of a biopsy from gastric mucosa showing sub-epithelial collagen accumulation (arrows), lymphocytic inflammation of the epithelium, and inflammation in the lamina propria (Magnification x100).

\section{DISCUSSION}

Our case does not fit the recent literature that has categorized all adult CG cases with CC including symptoms of chronic watery diarrhea, and other systemic diseases such as lymphocytic gastritis, celiac disease, lymphocytic colitis, and autoimmune disorders [5]. To date, there is no evidence of an association of CG with a pan systemic collagenous disease. When comparing to other described biopsy results of CG, our pathology was very similar. As seen in our case, the collagenous deposits showed surface epithelial injury and entrapped inflammatory cells, and the distribution in the antrum and body was variably patchy and diffuse [5]. She was started on omeprazole $40 \mathrm{mg}$ by mouth every twelve hours for treatment of her GERD symptoms. Although there seems to be no known or proven therapy for CG, 
our patient's symptoms were markedly improved with omeprazole and a low fat and high fiber diet. Repeat upper endoscopy one year later with surveillance biopsies showed stable and unchanged CG despite improvement of her symptoms.

Long-term maintenance therapy with oral budesonide was found to be efficacious and well tolerated for preventing relapse in patients with collagenous colitis [7], but there have also been many cases documenting spontaneous resolution of $\mathrm{CC}$ in literature [8]. Histological endpoints are difficult to evaluate because the sub-epithelial collagen deposits tend to be patchy, so treatment has most often focused on symptom resolution using anti-inflammatory medications [8]. Since our patient's symptoms resolved on high dose omeprazole, we felt that treating with steroids would likely be more harmful than beneficial at this stage in her disease. There is a possibility that like CC, her CG will spontaneously resolve on its own. There is no documentation of malignancy associated with chronic $\mathrm{CC}$ and $\mathrm{CG}$ to date.

\section{CONCLUSION}

To the best of our knowledge, this was the first case of collagenous involvement of the esophageal gastric junction in collagenous gastritis. She is the first adult patient who presented with collagenous gastritis with upper gastrointestinal symptoms with no manifestations of collagenous colitis, and no lower gastrointestinal symptoms including diarrhea which is consistent with pediatric type categorization of the disease. Considering the rarity of the disease, we feel that is still too premature to categorize collagenous gastritis into two distinct adult type and pediatric type disease. Our patient's symptoms resolved with a proton pump inhibitor, but histologically, our patient showed no improvement on one year esophagoduodenoscopy biopsy surveillance.

$* * * * * * * * *$

\section{Author Contributions}

Yousef Usta - Substantial contributions to conception and design, Acquisition of data, Analysis and interpretation of data, Drafting the article, Revising it critically for important intellectual content, Final approval of the version to be published

Denise Millstine - Substantial contributions to conception and design, Acquisition of data, Analysis and interpretation of data, Drafting the article, Revising it critically for important intellectual content, Final approval of the version to be published

Fredrick Kenny - Substantial contributions to conception and design, Acquisition of data, Analysis and interpretation of data, Drafting the article, Revising it critically for important intellectual content, Final approval of the version to be published

\section{Guarantor}

The corresponding author is the guarantor of submission.

\section{Conflict of Interest}

Authors declare no conflict of interest.

\section{Copyright}

(C) Yousef Usta et al. 2013; This article is distributed under the terms of Creative Commons attribution 3.0 License which permits unrestricted use, distribution and reproduction in any means provided the original authors and original publisher are properly credited. (Please see www.ijcasereportsandimages.com/copyright-policy.php for more information.)

\section{REFERENCES}

1. Colletti RB, Trainer TD. Collagenous gastritis. Gastroenterology 1989 Dec;97(6):1552-5.

2. Brain O, Rajaguru C, Warren B, Booth J, Travis S. Collagenous gastritis: Reports and systematic review. Eur J Gastroenterol Hepatol 2009 Dec;21(12):141924.

3. Ravikumara M, Ramani P, Spray CH. Collagenous gastritis: A case report and review. Eur J Pediatr 2007 Aug;166(8):769-3.

4. Suskind D, Wahbeh G, Murray K, Christie D, Kapur RP. Collagenous gastritis, a new spectrum of disease in pediatric patients: Two case reports. Cases J 2009 Jun 10;2:7511.

5. Leung ST, Chandan VS, Murray JA, Wu TT. Collagenous gastritis: Histopathologic features and association with other gastrointestinal diseases. Am J Surg Pathol 2009 May;33(5):788-98.

6. Lagorce-Pages C, Fabiani B, Bouvier R, Scoazec JY, Durand L, Flejou JF. Collagenous gastritis: A report of six cases. Am J Surg Pathol 2001 Sep;25(9):1174-9.

7. Bonderup OK, Hansen JB, Teglbjaerg PS, Christensen LA, Fallingborg JF. Long-term budesonide treatment of collagenous colitis: A randomised, double-blind, placebo-controlled trial. Gut 2009 Jan;58(1):68-72.

8. Freeman HJ. Complications of collagenous colitis. World J Gastroenterol 2008 Mar 21;14(11):1643-5. 
Access PDF of article on other devices

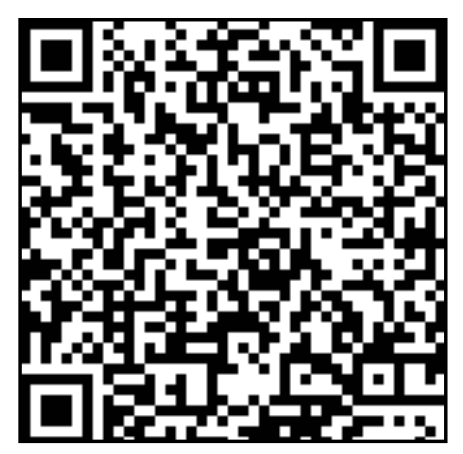

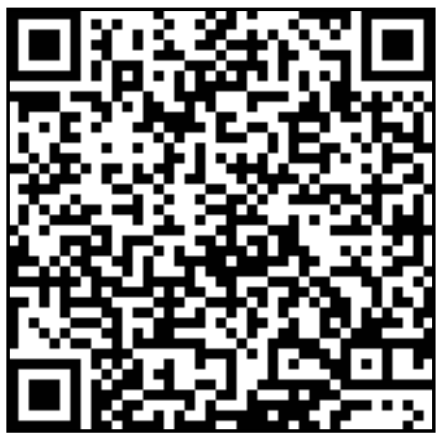

